\title{
Applications of Calculus in Real Life
}

\author{
Thida, Soe Soe \\ Department of Engineering Mathematics ,Technoligical University (Sagaing) \\ thida75mdy@gmail.com \\ drsoesoemdy@gmail.com
}

\begin{abstract}
In my paper, applications of calculus will be discussed by the gradient of a line or slope. Moreover, one of the applications of calculus, method of least square, fitting a straight line and a curve (parabola), will also be used.
\end{abstract}

Keywords - increasing (positive value), decreasing (negative), horizontal (zero) and vertical (undefined ).

\section{I .INTRODUCTION}

Calculus is a part of mathematics and is also used in Physics. With calculus, the changing conditions of a system may be found or observed. By being studied calculus, a system may be controlled from affecting to us.

The person such as, Engineers, scientists, and economists, who do not know the calculus well, they may not clever in their work and so they may not be good in their works.

In my paper, jobs opportunity of people, i.e., male and female who are over 18 years old and under 60 years old of government salary earners, company salary earners, workers and daily wager, in Mandalay Mahar Aung Myay township will be introduced by the average rate of change or secant slope and instantaneous rate of change or a gradient of a tangent line on a curve or tangent slope .

If the absolute value $|m|<1$, its inclination is not very steep (inclination $<30^{\circ}$ ). The line from left to right is increasing, the slope is a positive value, decreasing from right to left, the line has a negative slope. If a line is horizontal, then it has a constant slope but a vertical line has an undefined slope. The two lines are parallel if they have the same value of slopes and they are orthogonal to each other if the product of their values of slopes is equal to -1 .

(ii)Average and Instantaneous Rate of Changes or Secant Slope and Tangent Slope.

The average rate of change of $y$ or secant slope $\overline{P Q}$ of a function $y=f(x)$ with respect to $x$ over the interval $\left[x_{1}, x_{2}\right]$ is defined as the following

$\frac{\Delta y}{\Delta x}=\frac{f\left(x_{2}\right)-f\left(x_{1}\right)}{\left(x_{2}-x_{1}\right)}=\frac{f\left(x_{1}+h\right)-f\left(x_{1}\right)}{\hbar}=\frac{\text { rise }}{\text { run }}$

The instantaneous rate of change or tangent slope $m$ at $\left(x_{1}, f\left(x_{1}\right)\right)$ of a curve needs an approach that takes into account the behavior of the secant through $\mathrm{P}$ and nearby point $\mathrm{Q}$ as $\mathrm{Q}$ moves toward $\mathrm{P}$ along the curve or the length $\mathrm{h}$ of the interval over which the change occurs approaches zero. In symbol,

$m=\frac{d y}{d x}=\lim _{\Delta x \rightarrow 0} \frac{\Delta y}{\Delta x}=\lim _{\Delta \hbar \rightarrow 0} \frac{f\left(x_{1}+h\right)-f\left(x_{1}\right)}{\hbar}$

Equation (2) is also called the derivative of the function $f$ $(x)$ with respect to the variable $x$ at $\left(x_{1}, f\left(x_{1}\right)\right)$. It is a function and is denoted by $f^{\prime \prime}$.
The slope, $\mathrm{m}$, or gradient of a straight line, is a number may be obtained from the following equation

$y=m x+c$.

From Equation (3), the y-intercept or $\mathrm{c}$ may be obtained, either the value of slope is zero or if the initial position (x, y) and the slope, $\mathrm{m}$, are known. From Equation (2), if the starting point or initial point and end point or terminal point are known, the slope of a curve at a point or a tangent slope m may be calculated and then, the $y$-intercept or $\mathrm{c}$ may be obtained at the given two points.

The steepness of a line, $\mathrm{m}$, it is a number, may be obtained by taking the tangent of the angle measured above or below the horizontal line. In symbol,

$$
m=\tan \theta .
$$

\section{II . CONCEPTS OF SLOPES}

(i). The Behaviors or Characteristic Features of Tangent Slopes

Generally, there are two kinds of slopes, steep slope (high slope) and shallow slope (low slope). Besides, the other two kinds of slopes are flat slope (zero slope) and vertical (undefined slope).

The steepness, inclination, or declination shows the behaviors or characteristic features of the slope. Grade of a line is measured by the absolute value of the slope. A slope with a greater absolute indicates a steeper line.

Thus, not only a line, which is inclined an angle $45^{\circ}$ to the positive horizontal axis in counter-clockwise direction, but also a line, which is inclined an angle $45^{\circ}$ to the negative horizontal axis in counter-clockwise direction, is an arising line and has a value of slope +1 or $\mathrm{m}$ is equal to 1 .

If the absolute value $|m|>1$, inclination is fairly steep. If the inclination is between $45^{\circ}$ and $90^{\circ}$, the slope is positive and if the inclination is between $135^{\circ}$ and $180^{\circ}$, the slope is negative and the direction of the line, $\tan \theta$ is increasing, In both cases, the inclination or $\theta$ is assumed to be measured from the positive horizontal axis in counter clockwise direction.

Moreover, if a line which has its inclination angle $\theta$ $45^{\circ}$, i.e., from the positive horizontal axis in clockwise direction or from the positive horizontal axis in counter clockwise direction the line is a falling line and it has a slope $\mathrm{m}(-1)$.

If the absolute value $|m|<1$, its inclination is not very steep (inclination $<30^{\circ}$ ). The line from left to right is increasing, the slope is a positive value, decreasing from right to left, the line has a negative slope. If a line is horizontal, then it has a constant slope but a vertical line has an undefined slope. The two lines are parallel if they have the same value of slopes and they are 
orthogonal to each other if the product of their values of slopes is equal to -1 .

(ii)Average and Instantaneous Rate of Changes or Secant Slope and Tangent Slope

The average rate of change of $y$ or secant slope $\overline{P Q}$ of a function $y=f(x)$ with respect to $x$ over the interval $\left[x_{1}, x_{2}\right]$ is defined as the following

$\frac{\Delta y}{\Delta x}=\frac{f\left(x_{2}\right)-f\left(x_{1}\right)}{\left(x_{2}-x_{1}\right)}=\frac{f\left(x_{1}+h\right)-f\left(x_{1}\right)}{\hbar}=\frac{r i s e}{r u n}$

The instantaneous rate of change or tangent slope $m$ at $\left(x_{1}, f\left(x_{1}\right)\right)$ of a curve needs an approach that takes into account the behavior of the secant through $\mathrm{P}$ and nearby point $\mathrm{Q}$ as $\mathrm{Q}$ moves toward $\mathrm{P}$ along the curve or the length $\mathrm{h}$ of the interval over which the change occurs approaches zero. In symbol,

$m=\frac{d y}{d x}=\lim _{\Delta x \rightarrow 0} \frac{\Delta y}{\Delta x}=\lim _{\Delta h \rightarrow 0} \frac{f\left(x_{1}+h\right)-f\left(x_{1}\right)}{h}$

Equation (2) is also called the derivative of the function $f$ $(x)$ with respect to the variable $x$ at $\left(x_{1}, f\left(x_{1}\right)\right)$. It is a function and is denoted by $f^{\prime}$.

The slope, $\mathrm{m}$, or gradient of a straight line, is a number may be obtained from the following equation

$y=m x+c$.

From Equation (3), the y-intercept or c may be obtained, either the value of slope is zero or if the initial position $(\mathrm{x}, \mathrm{y})$ and the slope, $\mathrm{m}$, are known. From Equation (2), if the starting point or initial point and end point or terminal point are known, the slope of a curve at a point or a tangent slope m may be calculated and then, the y-intercept or c may be obtained at the given two points.

The steepness of a line, $\mathrm{m}$, it is a number, may be obtained by taking the tangent of the angle measured above or below the horizontal line. In symbol,

$$
m=\tan \theta \text {. }
$$

\section{The APPLICATION IN REAL LIFE}

In my paper, jobs opportunities of people, i.e., males and females who are over 18 and under 60 age of government salary earners, company salary earners, workers and daily wager, in Mandalay Mahar Aung Myay township will be discussed by means of slopes in two cases, negative and positive. Moreover, fitting a straight line and parabola will be presented by the method of least squares. All of them will be obtained for the following data shown in tables.

\begin{tabular}{|l|l|l|l|l|}
\hline \multirow{2}{*}{ Year } & \multicolumn{2}{|l|}{$\begin{array}{l}\text { Civil } \\
\text { earner }\end{array}$} & salary & \multicolumn{2}{c|}{$\begin{array}{l}\text { Company } \\
\text { salary earner }\end{array}$} \\
\cline { 2 - 5 } & F & M & F & M \\
\hline 2015 & 2090 & 842 & 2735 & 4250 \\
\hline 2016 & 1989 & 681 & 3255 & 4955 \\
\hline 2017 & 1953 & 756 & 4412 & 5178 \\
\hline
\end{tabular}

Table (1)

\begin{tabular}{|l|l|l|l|l|}
\hline \multirow{2}{*}{ Year } & \multicolumn{2}{|l|}{ Civil Labourer } & \multicolumn{2}{l|}{$\begin{array}{l}\text { Company } \\
\text { Labourer }\end{array}$} \\
\cline { 2 - 5 } & F & M & F & M \\
\hline 2015 & 8 & 274 & 536 & 1055 \\
\hline 2016 & 40 & 976 & 544 & 1049 \\
\hline 2017 & 23 & 507 & 110 & 305 \\
\hline
\end{tabular}

\section{Table (2)}

\section{(i) Negative Slope}

A line is decreasing from left to right. The slope is negative, i.e. $\mathrm{m}$ is negative.

The getting of the civil salary earners job for both female and male are decreasing from year 2015 to year 2016 because of their slopes having negative values -101 and -161 .

Moreover, the getting jobs of the civil salary earner for female is decreasing from year 2016 to year 2017 because of the negative value of the slope -36 from year 2016 to year 2017. The getting jobs of the civil labourers for female is decreasing from year 2016 to year 2017 because of the negative value of the slope - 17 from year 2016 to year 2017. The getting jobs of the daily wager's (Company Labourer) for female is decreasing from 2016 to 2017 because of the negative value of the slope -434 from year 2016 to year 2017.

The getting jobs of the civil labourer for male is decreasing from 2016 to 2017 because of the negative value of the slope 469 from year 2016 to year 2017.

The getting jobs of the company labourer for male is decreasing from year 2016 to year 2017 because of the negative value of the slope - 744 from year 2016 to year 2017 .

All of the above cases, calculus will be applied in real life shown as the followings.

\section{Civil Salary Earners' Jobs for Female}

$$
\begin{aligned}
& x_{1}=2015 ; x_{2}=2016 \\
& f\left(x_{2}\right)=1989 ; f\left(x_{1}\right)=2090 \\
& m=\frac{\Delta y}{\Delta x}=\frac{f\left(x_{2}\right)-f\left(x_{1}\right)}{x_{2}-x_{1}}=-101
\end{aligned}
$$

\section{Jobs of Civil Salary Earner for Female}

$$
\begin{aligned}
& x_{1}=2016 ; x_{2}=2017 \\
& f\left(x_{1}\right)=1989 ; f\left(x_{2}\right)=1953 \\
& m=\frac{\Delta y}{\Delta x}=\frac{f\left(x_{2}\right)-f\left(x_{1}\right)}{x_{2}-x_{1}}=\frac{1959-1989}{2017-2016}=-36<0 .
\end{aligned}
$$

\section{Civil Salary Earners' Jobs for Male}

$$
\begin{aligned}
& x_{1}=2015 ; x_{2}=2016 \\
& f\left(x_{2}\right)=681 ; f\left(x_{1}\right)=842 \\
& m=\frac{\Delta y}{\Delta x}=\frac{f\left(x_{2}\right)-f\left(x_{1}\right)}{x_{2}-x_{1}}=-161<0
\end{aligned}
$$

\section{Jobs of Workers for Female (Civil Labourer)}

$$
\begin{aligned}
& x_{1}=2016 ; x_{2}=2017 \\
& f\left(x_{1}\right)=40 ; f\left(x_{2}\right)=23 \\
& m=\frac{\Delta y}{\Delta x}=\frac{f\left(x_{2}\right)-f\left(x_{1}\right)}{x_{2}-x_{1}}=-17<0
\end{aligned}
$$




\section{Jobs of Workers' for male (Civil Labourer)}

$$
\begin{aligned}
& x_{1}=2016 ; x_{2}=2017 \\
& f\left(x_{1}\right)=976 ; f\left(x_{2}\right)=507 \\
& m=\frac{\Delta y}{\Delta x}=\frac{f\left(x_{2}\right)-f\left(x_{1}\right)}{x_{2}-x_{1}}=-469<0
\end{aligned}
$$

\section{Jobs of Daily Wager's for Females (Company Labourer)}

$$
\begin{aligned}
& x_{1}=2016 ; x_{2}=2017 \\
& f\left(x_{1}\right)=544 ; f\left(x_{2}\right)=110 \\
& m=\frac{4 y}{\Delta x}=\frac{f\left(x_{2}\right)-f\left(x_{1}\right)}{x_{2}-x_{1}}=-434<0
\end{aligned}
$$

\section{Jobs of Daily Wagers' for Males (Company Labourer)}

$$
\begin{aligned}
& x_{1}=2016 ; x_{2}=2017 \\
& f\left(x_{1}\right)=1049 ; f\left(x_{2}\right)=305 \\
& m=\frac{\Delta y}{\Delta x}=\frac{f\left(x_{2}\right)-f\left(x_{1}\right)}{x_{2}-x_{1}}=-744<0
\end{aligned}
$$

\section{(ii) Positive Slope}

A line is increasing from left to right. The slope is positive, i.e. $m>0$.

For company salary earners' jobs for female

$$
\begin{aligned}
& x_{1}=2015 ; x_{2}=2016 \\
& f\left(x_{2}\right)=3255 ; f\left(x_{1}\right)=2735 \\
& m=\frac{\Delta y}{\Delta x}=\frac{f\left(x_{2}\right)-f\left(x_{1}\right)}{x_{2}-x_{1}}=520
\end{aligned}
$$

The slope between two years from 2015to 2016 is greater than zero, $\mathrm{m}=520$.

The getting of the company salary earners' jobs for female is increasing from years 2015 to 2016, for the result of this slope is positive

Company Salary earners' jobs for male

$$
\begin{aligned}
& x_{1}=2015 ; x_{2}=2016 \\
& f\left(x_{1}\right)=4250 ; f\left(x_{2}\right)=4955 \\
m= & \frac{\Delta y}{\Delta x}=\frac{f\left(x_{2}\right)-f\left(x_{1}\right)}{x_{2}-x_{1}}=\frac{4955-4250}{2016-2015}=705
\end{aligned}
$$

The slope between years 2015 and 2016 is greater than 0 and positive. Its value is 705 .

The getting of the company salary earners' jobs for male is increasing from 2015 to 2016.

Worker's jobs for female

$$
\begin{aligned}
& x_{1}=2015 ; x_{2}=2016 \\
& f\left(x_{1}\right)=8 ; f\left(x_{2}\right)=40 \\
m= & \frac{\Delta y}{\Delta x}=\frac{f\left(x_{2}\right)-f\left(x_{1}\right)}{x_{2}-x_{1}}=\frac{40-8}{2016-2015}=32
\end{aligned}
$$

The slope from year 2015 to year 2016 is greater than 0 and positive, for $\mathrm{m}=32$.

The getting of the worker's jobs for female is increasing from 2015 to 2016.

\section{Jobs of Civil Salary earner for male}

$$
\begin{aligned}
& x_{1}=2016 ; x_{2}==2017 \\
& f\left(x_{1}\right)=681 ; f\left(x_{2}\right)=756 \\
& m=\frac{4 y}{\Delta x}=\frac{f\left(x_{2}\right)-f\left(x_{1}\right)}{x_{2}-x_{1}}=75>0
\end{aligned}
$$

The getting jobs of the for male is increasing from 2016 to 2017 because of the positive value of the slope 75 from year 2016 to year 2017.

\section{Jobs of Company's salary earner's for female}

$$
\begin{aligned}
& x_{1}=2016 ; x_{2}=2017 \\
& f\left(x_{1}\right)=3255 ; f\left(x_{2}\right)=4412 \\
& m=\frac{\Delta y}{\Delta x}=\frac{f\left(x_{2}\right)-f\left(x_{1}\right)}{x_{2}-x_{1}}=1157>0
\end{aligned}
$$

The getting jobs of Company salary earner's for female is increasing from 2016 to 2017 because of the positive value of the slope 1157 from year 2016 to year 2017.

\section{Jobs of company salary earners' for male}

$$
\begin{aligned}
& x_{1}=2016 ; x_{2}=2017 \\
& f\left(x_{1}\right)=4955 ; f\left(x_{2}\right)=5178 \\
& m=\frac{4 y}{\Delta x}=\frac{f\left(x_{2}\right)-f\left(x_{1}\right)}{x_{2}-x_{1}}=223>0
\end{aligned}
$$

The getting jobs of the company salary earners' for male is increasing from 2016 to 2017 because of the positive value of the slope 223 from year 2016 to year 2017.

\section{CONCLUSIONS}

In my conclusion, slope may be applied both in separation of a huam ability suh as medicine technological, education, economics and weather information ( rainy, hot ,cold ).So it can be applied in real life.

\section{ACKNOWLEDGMENT}

Firstly, I would like to give my acknowledgement to my head Dr. Soe Soe for her encourage let to perform this paper. Secondly as she read and advised me to perform my paper the best. Finally, I am also grateful to all of the members who accepted my paper to be published in journal. 


\section{Appendix A}

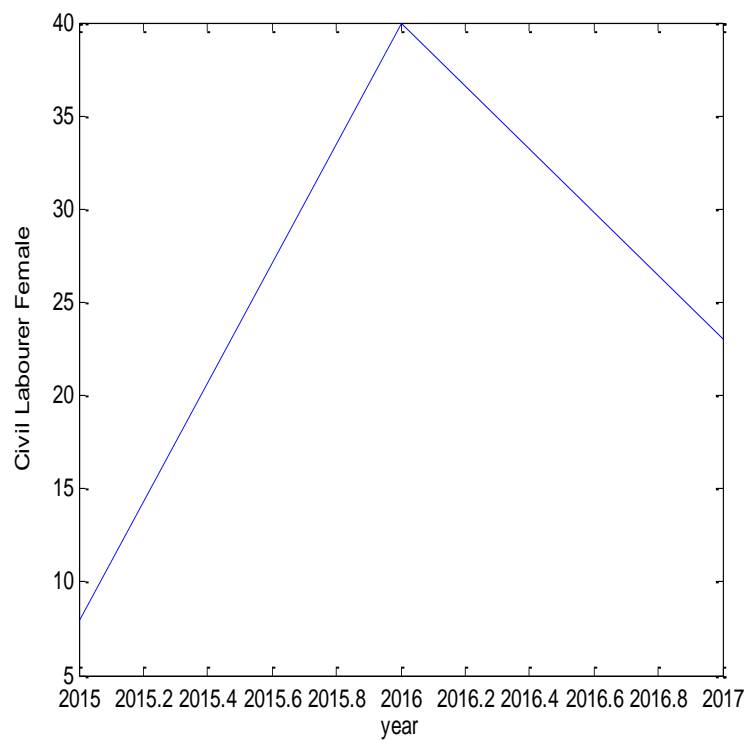

Figure 1(a)

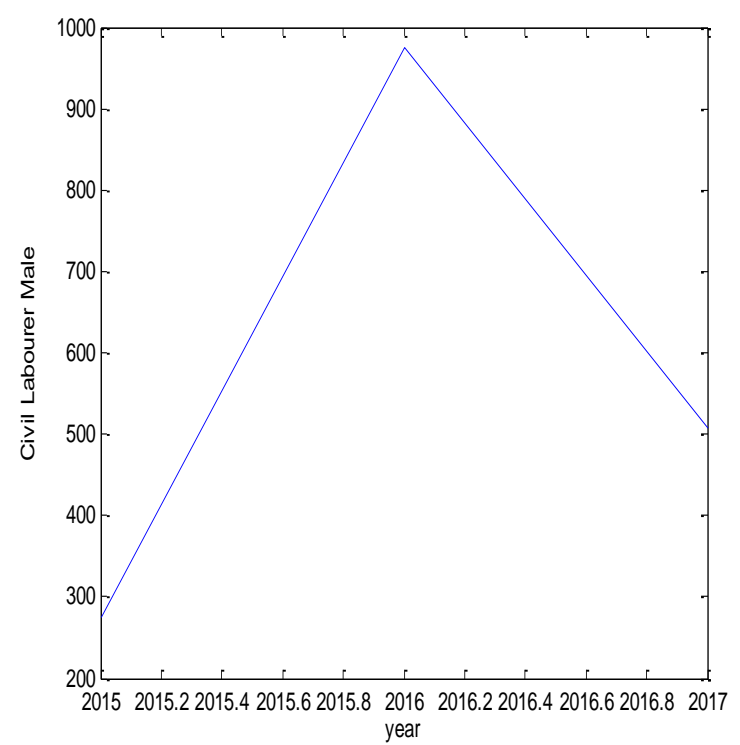

Figure 2(a)

\section{Appendix B}

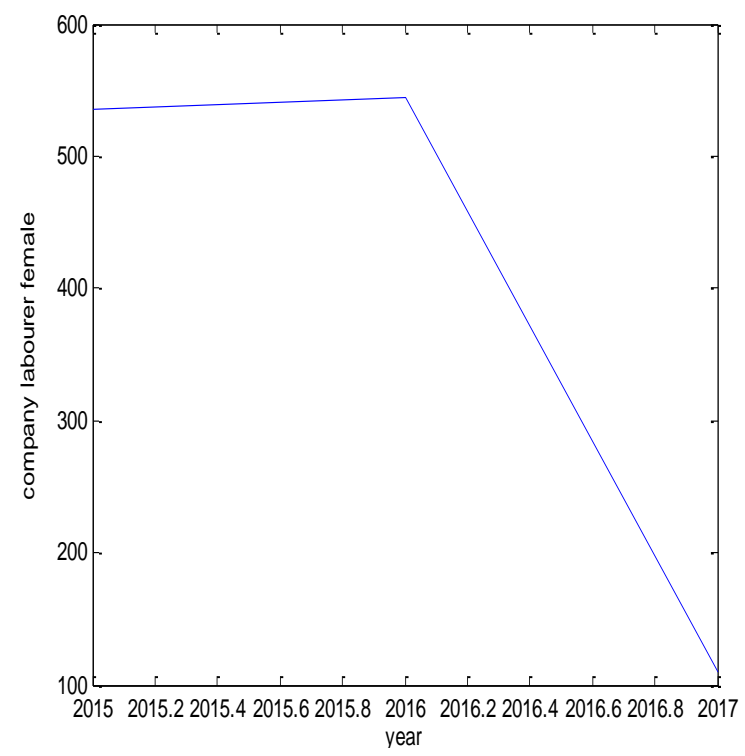

Figure 1(b)

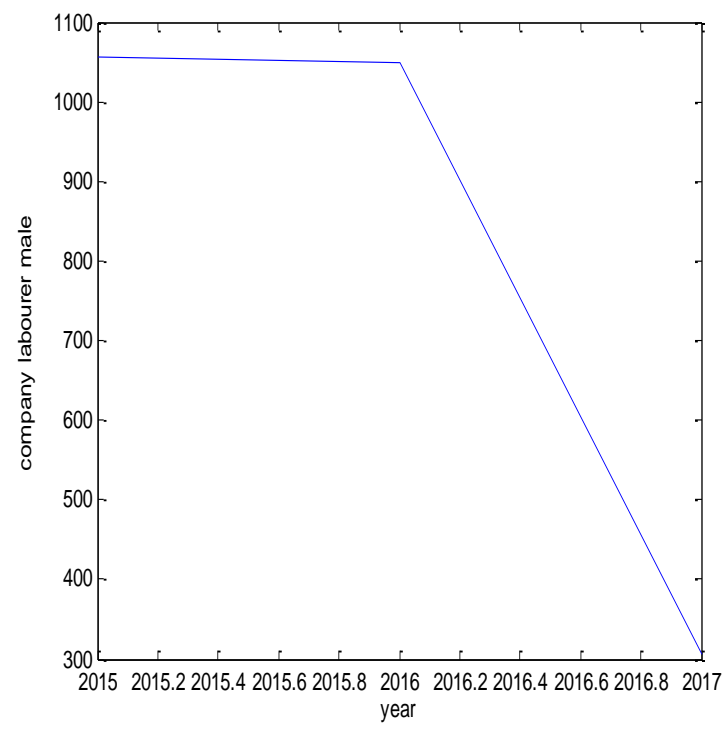

Figure 2(b) 


\section{Appendix A}

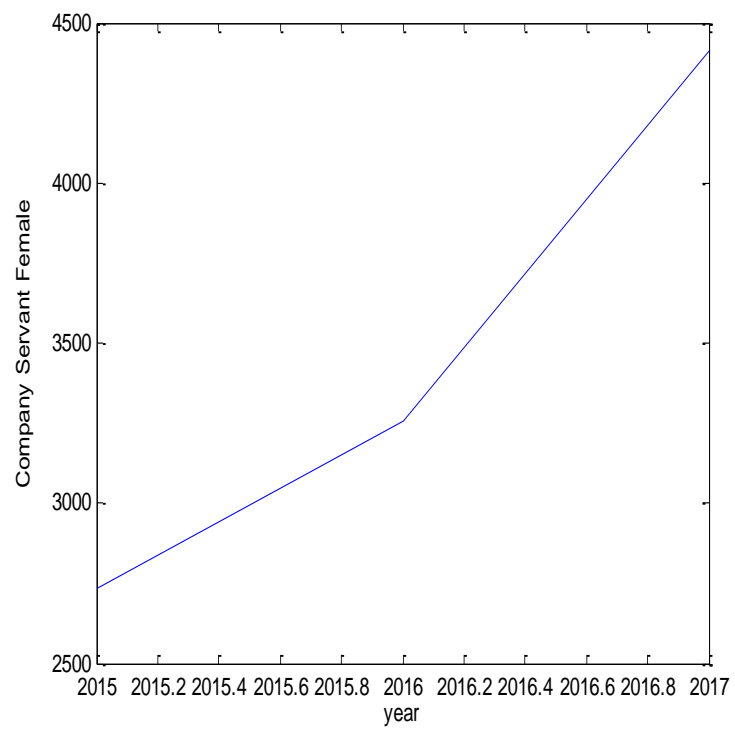

Figure 3(a)

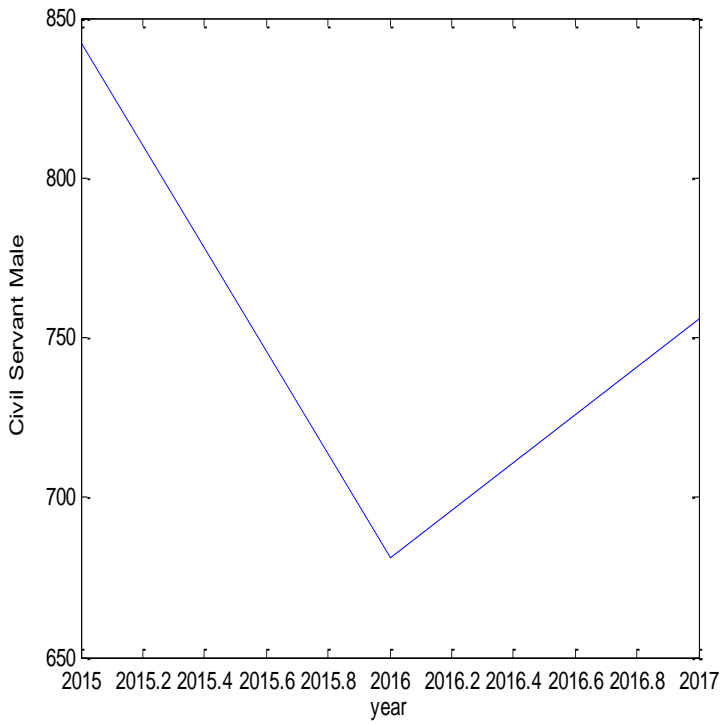

Figure 4(a)

\section{Appendix B}

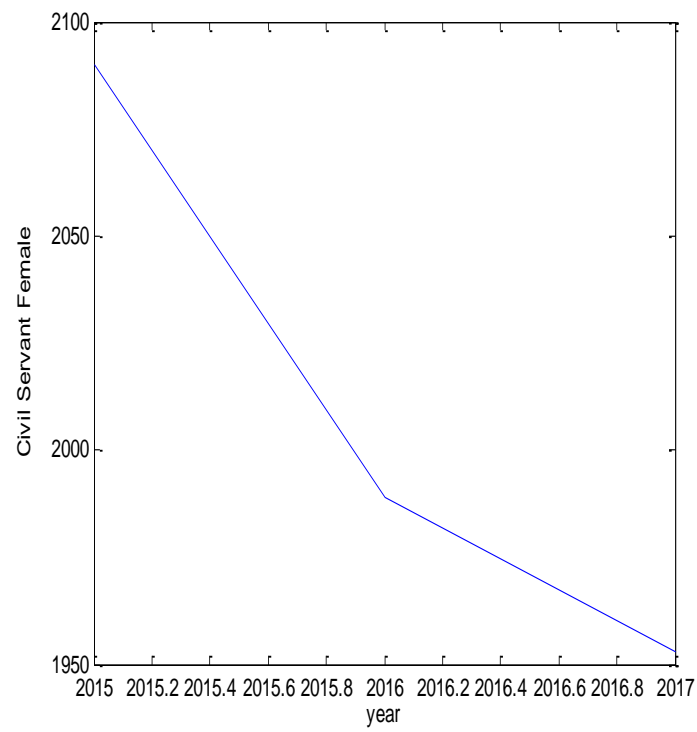

Figure 3(b)

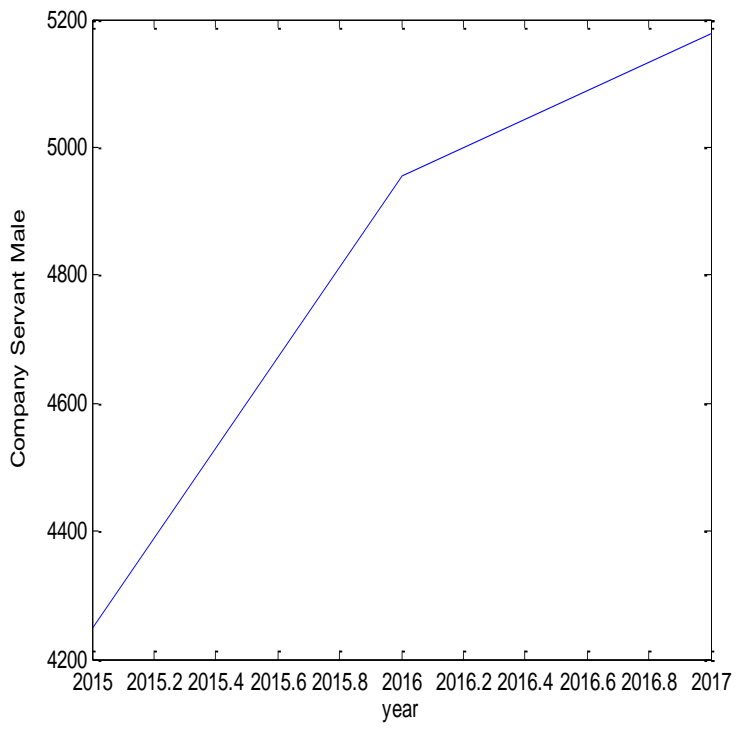

Figure 4(b) 


\section{References}

[1] Clapham,C;Nicholson,J. (2009), "Oxford Concise Dictionary of Mathematics, Gradient"(PDF). Addison-Wesley. p.348. Archived from the original (PDF) on 29 October 2013.Retrived 1 September 2013

[2] Weisstein, Eric W. "Slope" Math World - A Wolfram Web Resource . Archived from the original on 6 December 2016 .Retrieved 30 October 2016.

[3] Further Mathematics Units 3\&4 VCE( revised ). Cambridge Senior Mathematics. 2016.

ISBN 9781316616222 -via Physical Copy .

[4] "Slope of a line (Coordinate Geometry)". Math open Reference.2009. Retrieved 30, October 2016, interactive. Retrieved from " https: // en. Wikipedia. Org / wmndex.php?

[5] Slope from two points formula (simplifying Math) (2018)

[6] Thomas' calculus (Twelfth Edition) 